\title{
Methodology of Roadway Impacts Modelling to Predict the Fatigue Life of Vehicles Parts
}

\author{
D. Zezyulin, V. Makarov, S. Ogorodnov, V. Belyakov \\ Nizhny Novgorod State Technical University named after R.E. Alekseev, \\ Department of "Cars and tractors" \\ GSP-41, 24, Minin str., Nizhniy Novgorod, 603950, Russia \\ Phone: 8 (831) 436-63-73 \\ e-mail: nauka@nntu.nnov.ru
}

\begin{abstract}
This paper describes methodology of disturbances formation from the road surface to predict durability of suspension elements and the supporting system of light commercial vehicles. This methodology is designed on the basis of theoretical and experimental researches. Classification of asphalt concrete roads is formed taking into account deterioration of the coverage. It gives models of the road profiles representing public roads. The synthesis method of sequences of ordinates of road profiles is based on the use of probabilistic characteristics of microprofile. It shows the measuring equipment to determine the road sections with different states of coverage by the length of the routes selected for the research. It presents the results of the selection and justification of the range of modes of motion reflecting the real operating conditions of vehicles in urban environments. The results are obtained by carrying out statistical studies of the traffic intensity on the selected routes using a web mapping service.
\end{abstract}

Keywords: operating conditions, roads microprofile, light commercial vehicle, durability

\section{Introduction}

Probabilistic methods for quantifying the durability of suspension elements and the supporting systems in motor vehicles are considered the most perfect now. These methods allow us to take into account the random nature of changing parameters that affect the dynamic characteristics of the systems [1]. The main issue when calculating the vehicles details resource is adequate modeling of operational stress loading. It is necessary to have the values and nature of roadway impacts, the range of movement modes, reflecting the real operating conditions of vehicles in urban environments for the calculation. The main cause of dynamic loads determining the durability of structural elements of cars is oscillatory process occurring in the car while driving on rough roads.

This is discussed in details in [2-5], in [2] The model of operational loading of the test components of vehicles is not based on analysis of statistical data of car traffic, and 
model of road impact is not spatial. In the sources [3-5] in the formation of the model of distribution of car mileage on different types of roads is used insufficiently substantiated or outdated statistical findings. Currently, there is the growth of rate of developing of light commercial vehicles designs and limitation of approaches to modeling of their operational loading in the task of quantitative assessment of vehicle durability. Therefore, car manufacturers are looking for advanced technologies to produce a rapid and accurate data on the road impacts.

\section{Features of a road microprofile}

\subsection{Classification of asphalt concrete roads}

During the research the classification of asphalt concrete roads in view of deterioration of the coating is formed. Formation of this classification was based on the systematization of the experimental data on the number, size and nature of the alternation of roughness.

The road is divided into the following groups according to the coating: the road in good condition, a little worn road, badly worn road and a broken road. You can see detailed specifications of listed groups below.

\subsection{Mathematical models of road profiles representing public roads}

Formation of mathematical models of generated set (library) of road profiles representing public roads in Russia was carried out by the example of roads in several districts of Nizhniy Novgorod.

The methodology outlined in [6] is used for modeling of a microprofile of asphalt concrete road. The parameters of the correlation function of a microprofile of automobile road will be presented in Section 2.3.

The degree of deterioration of road surfaces is modeled by constructing separate laws on the basis of the distribution of roughness from the experimentally obtained data on the number, size and nature of their alternation (distances between the asperities).

The exponential law of distribution is most suitable for mathematical modeling [7]. In determining the number of roughnesses of their length and the distance between the roughnesses we have the following dependence

$$
\begin{aligned}
& n(x)=A \frac{1}{\lambda} e^{-\frac{x}{\lambda}}, \\
& x=0,5\left(x_{i}+x_{i+1}\right),
\end{aligned}
$$

where $A=a \cdot \Delta x, A, a, x>0$ - parameters of this distribution, $x_{i+1}=x_{i}+\Delta x, \Delta x-$ discretization step of sizes of roughnesses, $a$ and $\lambda$ - empirical coefficients.

The results of the analysis conducted by the authors are the dependences to describe the asphalt urban roads. These parameters are summarized in Table 1. 
D. Zezyulin et al. - Acta Technica Jaurinensis, Vol. 7., No. 3., pp. 267-279, 2014

Table 1. The averaged model parameters of deterioration for road sections

\begin{tabular}{|c|c|c|c|c|c|c|c|}
\hline \multirow[t]{2}{*}{ № } & \multirow{2}{*}{$\begin{array}{c}\text { Characteristics of a } \\
\text { road }\end{array}$} & \multirow{2}{*}{$\begin{array}{c}\text { Type of } \\
\text { roughness }\end{array}$} & \multicolumn{2}{|c|}{$\begin{array}{c}\text { Size } \\
\text { parameters }\end{array}$} & \multicolumn{2}{|c|}{$\begin{array}{l}\text { Distance } \\
\text { settings }\end{array}$} & \multirow{2}{*}{$\begin{array}{c}\text { The average } \\
\text { depth of } \\
\text { roughness, } \\
\text { cm }\end{array}$} \\
\hline & & & $a$ & $\lambda$ & $a$ & $\lambda$ & \\
\hline \multirow{2}{*}{1} & \multirow{2}{*}{$\begin{array}{l}\text { Road in good } \\
\text { condition }\end{array}$} & Potholes & - & - & - & - & - \\
\hline & & Cracks & - & 1 & 180 & 5 & - \\
\hline \multirow{2}{*}{2} & \multirow{2}{*}{ Little worn road } & Potholes & 185 & 15 & 100 & 15 & 1 \\
\hline & & Cracks & - & 2 & 120 & 5 & - \\
\hline \multirow{2}{*}{3} & \multirow{2}{*}{ Badly worn road } & Potholes & 100 & 45 & 110 & 6 & 2 \\
\hline & & Cracks & - & 3 & 60 & 5 & - \\
\hline 4 & Broken road & Potholes & 190 & 150 & 190 & 5 & 3 \\
\hline
\end{tabular}

Distributions of roughnesses depending on the length and distance between each other are illustrated by Figures 1-2.

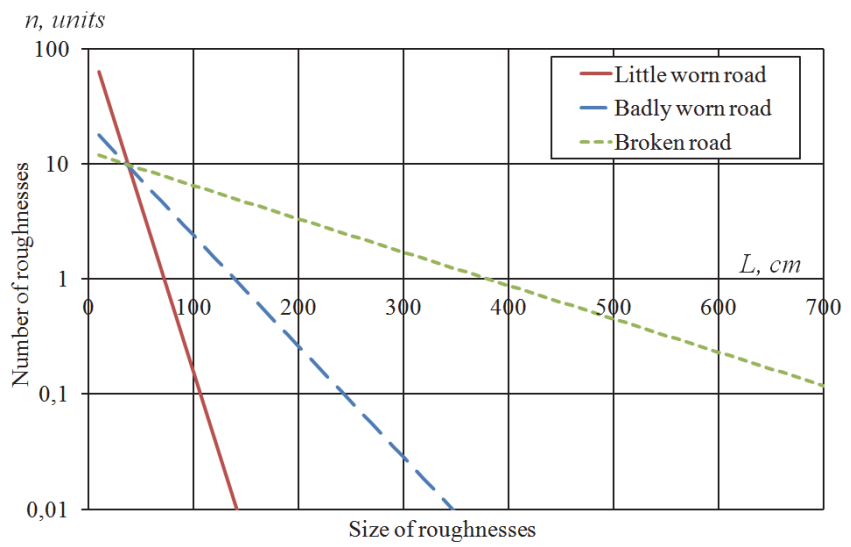

Figure 1. The distribution of roughnesses depending on the length 


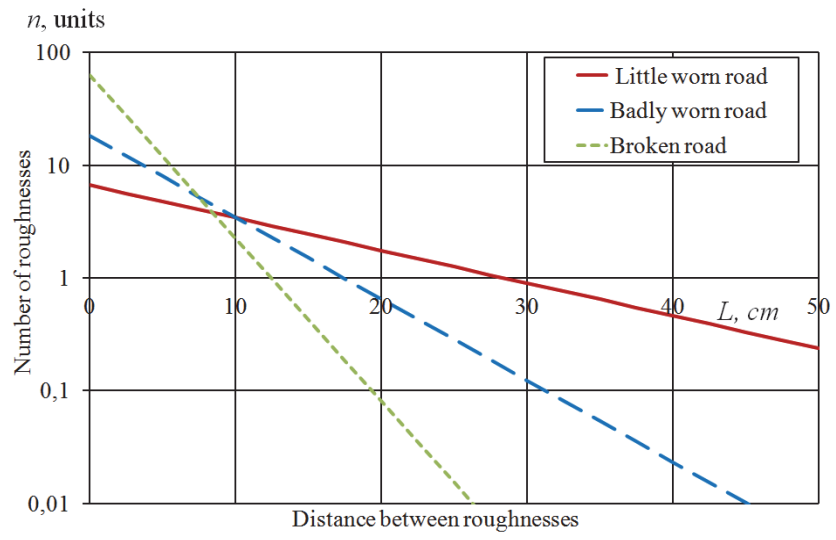

Figure 2. The distribution of roughnesses depending on the distance between each other

\subsection{Generating of a road microprofile}

Function of a microprofile of any road can be represented as a superposition of harmonic functions with different frequencies, amplitudes and phase angles, which were chosen so that the characteristics of the random process (average quadratic deviation, variance, the spectral density, the correlation function) began to coincide with similar characteristics of real roads.

The synthesis of numerical sequences of ordinate traffic profiles of the library was based on the probabilistic characteristics of microprofile. In the proposed program we added the roughness distributions characterizing the state of the road surface.

Let us consider the basic steps of generating of the road microprofile as a table function, which characterizes the dependence of the change of roughnesses height versus length of path. The method is based on algorithms for numerical simulation of stationary normal random processes with the use of common types of correlation functions [6].

Let us achieve the goal to receive the numerical sequence of ordinates of road profile. Here we assume that the sequence of random numbers must satisfy the stationarity, ergodicity and also must be normally distributed and have a correlation function of the exponential-cosine form:

$$
R(\tau)=R(0) e^{-\omega_{*}|\tau|} \cos \omega_{*} \tau
$$

where $R(0)=\sigma^{2}$ - dispersion of road microprofile; $\omega_{*}=\alpha V$ and $\omega_{0}=\beta V-$ parameters of the correlation function, e.g. $\alpha=0,22, \beta=0,44(1 / \mathrm{m})-$ asphalt road, $V$ $(\mathrm{M} / \mathrm{c})$ - speed; $\sigma$ - average quadratic deviation of a road microprofile.

Algorithm for obtaining the ordinates of microprofile consists of the following sequence of operations [6]:

1. First step is to obtain a uniformly distributed pseudo-random number sequence. 
2. Then normally distributed sequence is formed from a uniformly distributed one.

3. At the last stage we have a normal-distributed "white noise". A pseudo-random number sequence with the given "color" of the spectrum must be obtained. For this purpose the "white noise" is passed through a digital filter with the specified parameters.

\section{Determination of the average statistical operating conditions of light commercial vehicles in urban environments}

\subsection{Route selection for research}

The main criterion for selecting routes for further research within Nizhny Novgorod is the presence of frequent changes of areas with different state of the roadway, as well as elements of the road network (tram tracks, rail crossings, etc.).

\subsection{Experimental work to determine the states of coverage by the length of routes selected for the research}

Experimental work to determine the states of coverage by the length of routes selected for the research was carried out with the use of the car GAZ 2310 "Sable".

The vehicle was equipped with the following instrumentation:

1. System contactless measurement of motion parameters (GPS-technology) Racelogic VBOX 20SL3 20Hz GPS Data Logger With Slip, Pitch and Roll Angle (Figure 3).
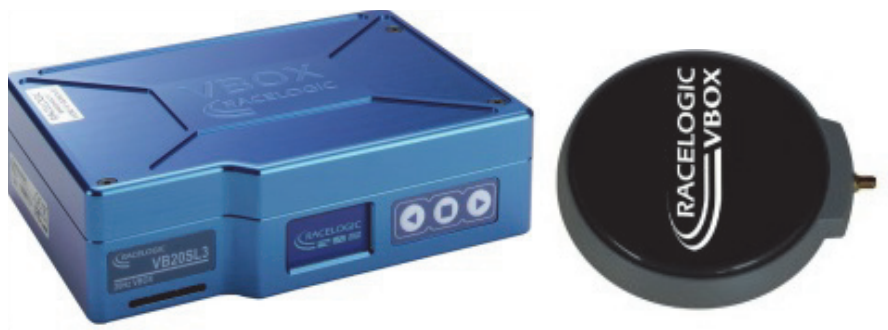

Figure 3. Data acquisition unit RaceLogic system (right) and the appearance of antennas (left)

2. The data acquisition system for dynamic testing DC-204R from the acceleration sensor ARJ-AD (Figures 4-5). 

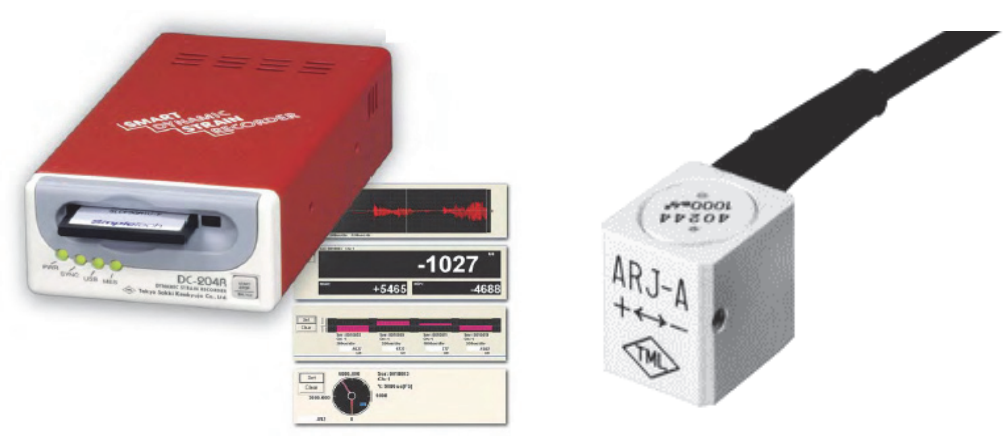

Figure 4. Recording device DC-204R and accelerometer ARJ-AD

The initial stage of experimental research was the series of races on the GAZ 2310 on road profiles selected as reference (classification) with different speeds. Example of the measured effects of roads by equipment is shown in Figure 5. As a result, database was created for each road profile (Figure 6). Databases contain oscillation parameters (vertical acceleration of the unsprung mass of vehicle) versus the longitudinal velocities of the vehicle. According to the testimony of the median longitudinal velocity and average square value of the vertical acceleration on the path can be determined indirectly by road surface condition, and as a consequence, the distribution pattern of roughnesses.

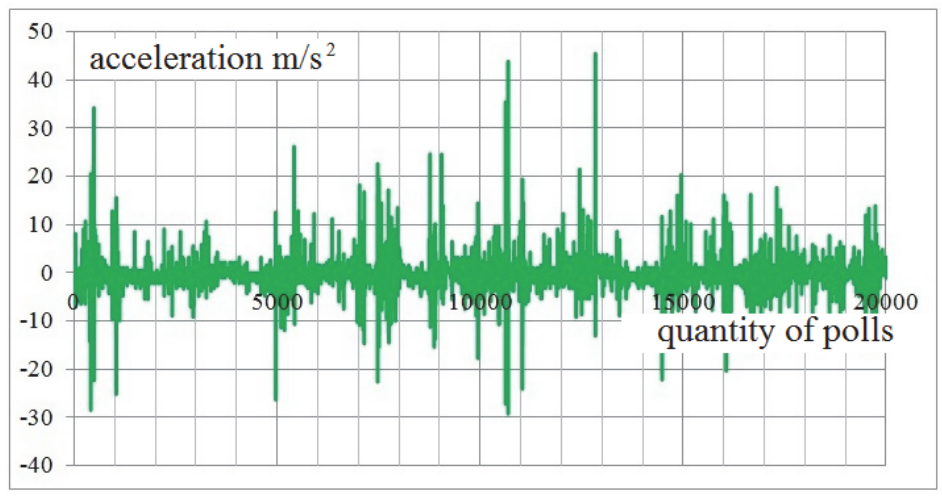

Figure 5. Example of measuring of the road impact 


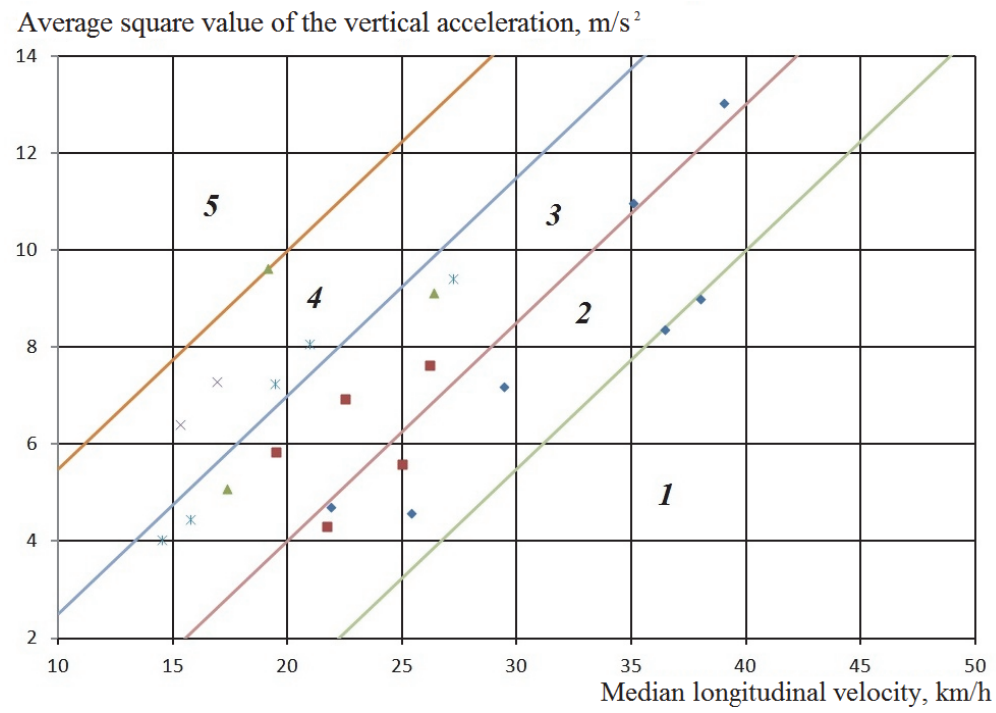

Figure 6. Influence of the vehicle speed on the vertical acceleration of the unsprung mass of vehicle when driving on typical road coverings: 1 - Road in good condition, 2 -

Little worn road, 3 - Badly worn road, 4 - Broken road, 5 - Elements of the road network (tram tracks, crossings, etc.). The dots show the experimental data

The main stage of experimental research was the implementation of movement on the car GAZ 2310 with the measuring equipment on selected routes. Function of control the vehicle movement is implemented by using GPS-receiver system Racelogic VBOX, and memory accumulate navigation data and data on speeds.

\subsection{Share distribution of the road sections with different states of coverage for a total length of routes}

To determine the share distribution of road sections with different quality coverage for a total length of routes that pass through the roads of the territory under consideration (Nizhny Novgorod), analysis of graphs of unsprung mass vertical acceleration GAZ 2310 was conducted.

Reverse operation of finding perturbations using the oscillation parameters at fixed velocities gives the characteristic of individual section flatness of the investigated roads. Analysis of the mean-square value of the vertical accelerations of unsprung mass and longitudinal velocities allows in accordance with the characteristics shown in Figure 6, to differentiate sections of road with different deteriorations by the total length of routes (Figure 7). 


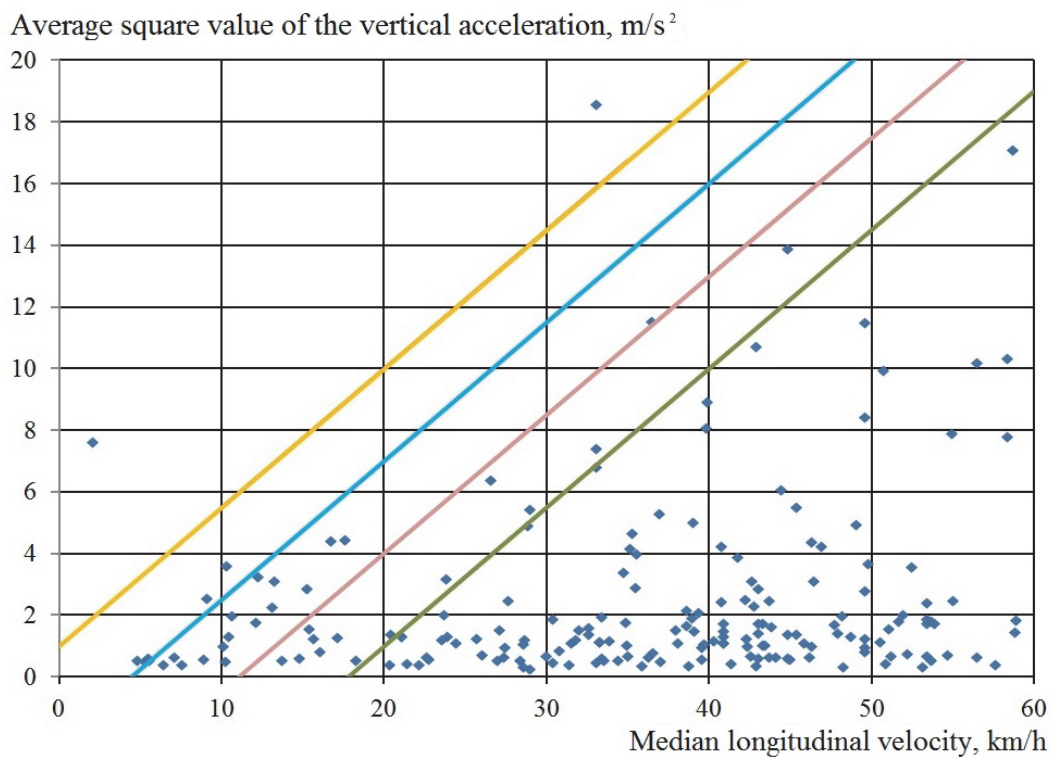

Figure 7. Example of differentiation of road sections with different deteriorations (shown by dots) using the ratio of the vertical acceleration of the unsprung mass and longitudinal velocities of the vehicle

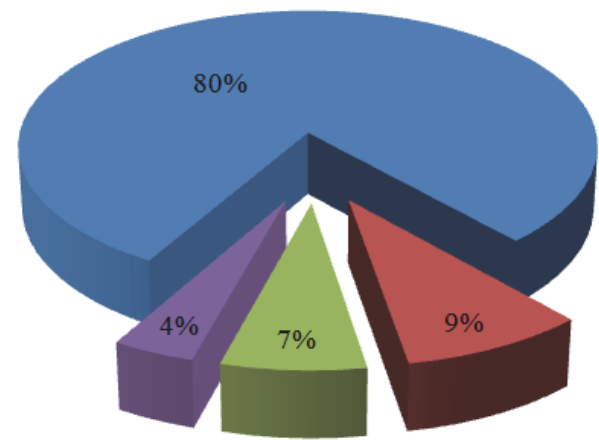

- Road in good condition

- Little worn road

- Badly worn road

Broken road

Figure 8. Share distribution of length of road sections with different state of coverage for the routes in question (experimental results)

\subsection{Modeling of the velocity distribution of vehicles on roads with different states of coverage}

Statistical studies of the traffic intensity on selected routes were carried out using a web mapping service. Analysis of the travel time on selected routes was produced based on the speed. The total recording of traffic intensity on the routes was equal more than 120 hours and about $3500 \mathrm{~km}$. Figure 9 shows the share distribution of time of car traffic on roads with different deterioration. 


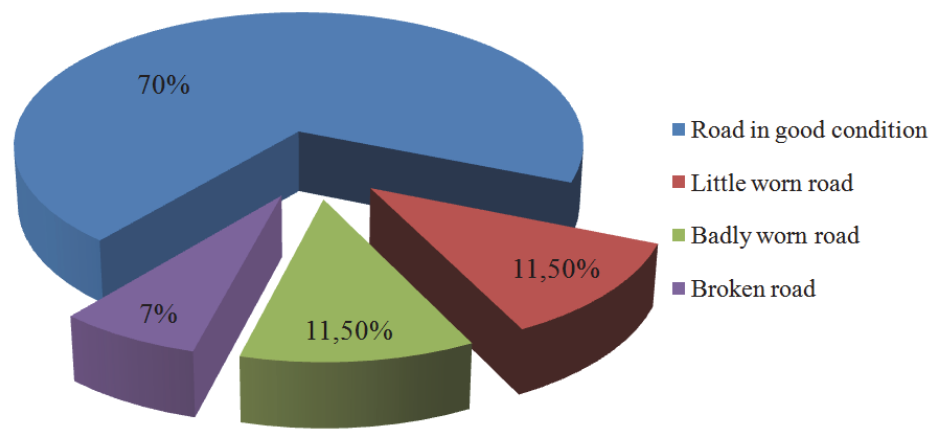

Figure 9. Share distribution of time of car traffic on roads with different deterioration (results of research of road traffic)

Research results were the statistical data on the distribution of vehicle speeds differentially for each state of the roads encountered on selected routes.

For the roads in good condition the distribution of mileage time as a function of speed is described using the normal law of distribution.

$$
\begin{gathered}
\varphi(V)=\frac{\Delta V}{\sigma_{V} \sqrt{2 \pi}} e^{-\frac{(V-\bar{V})^{2}}{2 \sigma_{V}^{2}}}, \\
V=0,5\left(V_{i}+V_{i+1}\right),
\end{gathered}
$$

where $\varphi(V)$ - relative travel time at a predetermined speed, $V_{i+1}=V_{i}+\Delta V, \Delta V$ - discretization step $(\Delta V=5 \mathrm{~km} / \mathrm{h}), \bar{V}$ - average speed, $\sigma_{V}$ - the mean square deviation from the average speed. For roads in good condition $\bar{V}=38 \mathrm{~km} / \mathrm{h}, \sigma_{V}=9$ $\mathrm{km} / \mathrm{h}$.

For other types of roads the distribution of the time of motion at different speeds looks as follows:

$$
\begin{gathered}
\varphi(V)=(a-b V)\left[\sum_{j=c}^{d}(a-j b \Delta V)\right]^{-1}, \\
V=0,5\left(V_{i}+V_{i+1}\right),
\end{gathered}
$$

where $\varphi(V)$ - relative travel time at a predetermined speed, $V_{i+1}=V_{i}+\Delta V, \Delta V$ - discretization step, $(\Delta V=5 \mathrm{~km} / \mathrm{h}), c=V_{H} / \Delta V, d=V_{K} / \Delta V, V_{H}-$ minimum limit of beginning of changing the speed $\left(V_{H}=5 \mathrm{~km} / \mathrm{h}\right), V_{K}$ - final speed (for greater speed the studies were not performed).

Table 2 contains the parameters for the mathematical description of the different states of the roadway. 
Table 2. Parameters in the formula

\begin{tabular}{|c|c|c|}
\hline \multirow{2}{*}{ Type of road } & \multicolumn{2}{|c|}{ Coefficients } \\
\cline { 2 - 3 } & $a$ & $b$ \\
\hline Little worn road & 0,04 & $1500^{-1}$ \\
\hline Badly worn road & 0,045 & $9 * 11000^{-1}$ \\
\hline Broken road & 0,05 & $1000^{-1}$ \\
\hline
\end{tabular}

\subsection{Calculation of the relative time of influence of each road profile in the general run of the car}

By the relative influence time of a certain type of road roughness you can jump by dividing the mileage on this road at speed and normalize the obtained values.

The modeling of operational loading is made on the basis of data on the impact time of all roads (or roads in a given ratio). This step is creation of mixed block of loading. Mixed blocks of loading are built using private blocks of loading for each mode of operation in accordance with their share in the working time of movement. Mode of operation is the movement of vehicle on a certain road with a certain velocity. Table 3 was built in accordance with the data. Figure 10 shows a graphical interpretation of the distribution of the relative time of influence.

Table 3. Relative time of influence of the roadway at different modes

\begin{tabular}{|c|c|c|c|c|}
\hline \multirow{2}{*}{$\begin{array}{c}\text { Speed, } \\
\boldsymbol{k m} / \boldsymbol{h}\end{array}$} & $\begin{array}{c}\text { Share of time of coverage influence, \% } \\
\text { condition }\end{array}$ & Little worn road & Badly worn road & $\begin{array}{c}\text { Broken } \\
\text { road }\end{array}$ \\
\hline 5 & 0,018552 & 1,925996 & 2,114213 & 1,457062 \\
\hline 10 & 0,121911 & 1,750906 & 1,902792 & 1,295166 \\
\hline 15 & 0,588375 & 1,575815 & 1,69137 & 1,133271 \\
\hline 20 & 2,085567 & 1,400725 & 1,479949 & 0,971375 \\
\hline 25 & 5,429413 & 1,225634 & 1,268528 & 0,809479 \\
\hline 30 & 10,38102 & 1,050543 & 1,057106 & 0,647583 \\
\hline 35 & 14,57759 & 0,875453 & 0,845685 & 0,485687 \\
\hline 40 & 15,03453 & 0,700362 & 0,634264 & 0,323792 \\
\hline 45 & 11,38813 & 0,525272 & 0,422843 & 0,161896 \\
\hline 50 & 6,335394 & 0,350181 & 0,211421 & 0 \\
\hline 55 & 2,58853 & 0,175091 & 0 & - \\
\hline 60 & 0,776768 & 0 & - & - \\
\hline 65 & 0,171194 & - & - & - \\
\hline 70 & 0,02771 & - & - & - \\
\hline
\end{tabular}




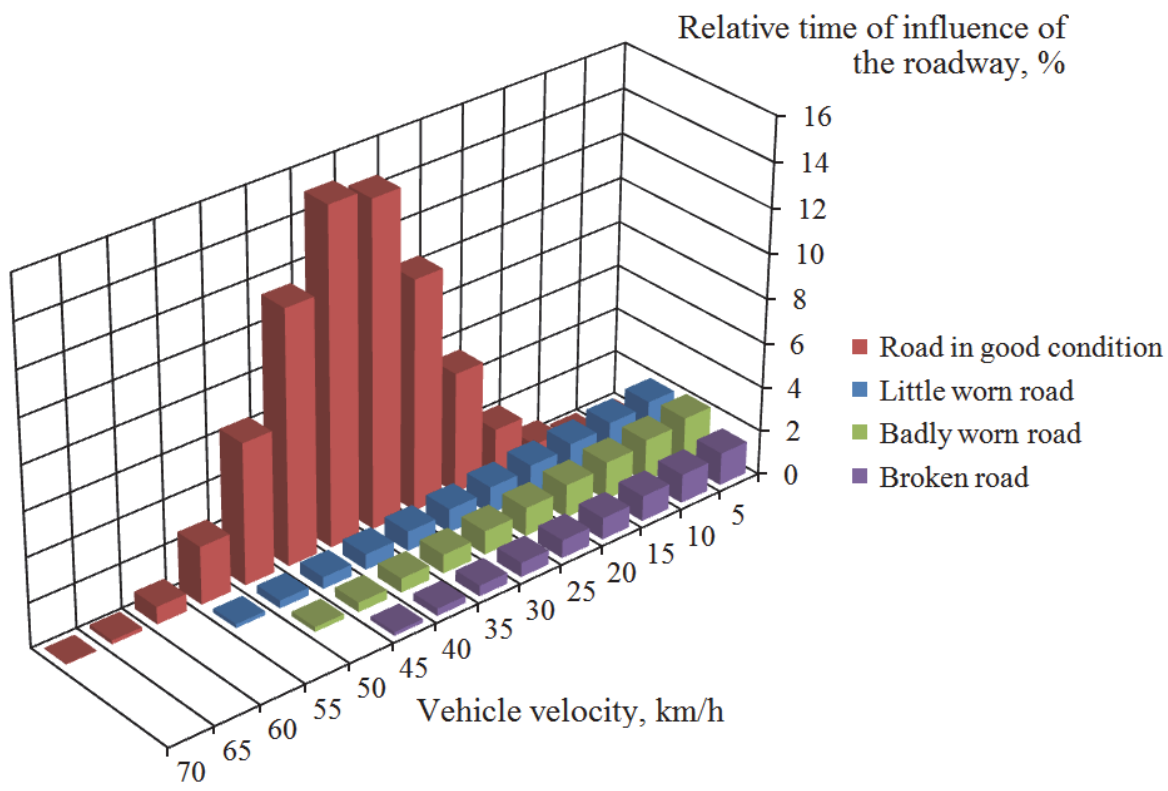

Figure 10. Graphical interpretation of the distribution of the relative time of influence of the roadway at different modes

\subsection{Methodology of modeling of roadway impacts for life prediction of the parts of light commercial vehicles}

The set of initial data for modeling of the loading history of the suspension and the supporting system characterizing the operating conditions of light commercial vehicles includes two components: 1) library of implementations of roughnesses corresponding to different road surfaces; 2) table of the relative time distribution of roadway influence at different modes.

The first step in roadway impacts modeling to predict the fatigue life of suspension components and supporting system of vehicles is the synthesis of stochastic road profile processes. It is necessary to take into account the data on deterioration of the road surface, obtained by the sampling processing of potholes on specific areas.

The next step is to get the share distribution of road sections with different state of coverage for a given territory using the data obtained in the course of experiments on special areas and routes (see sections 3.2 and 3.3.).

Share distribution is necessary for analyzing running time of vehicle on road sections with different cover condition. Calculation of relative time of influence of the roadway at different speeds of vehicle is produced by dividing the total length of the sections relating to the same classification group and passing the same average speed into this speed (see section 3.5). 


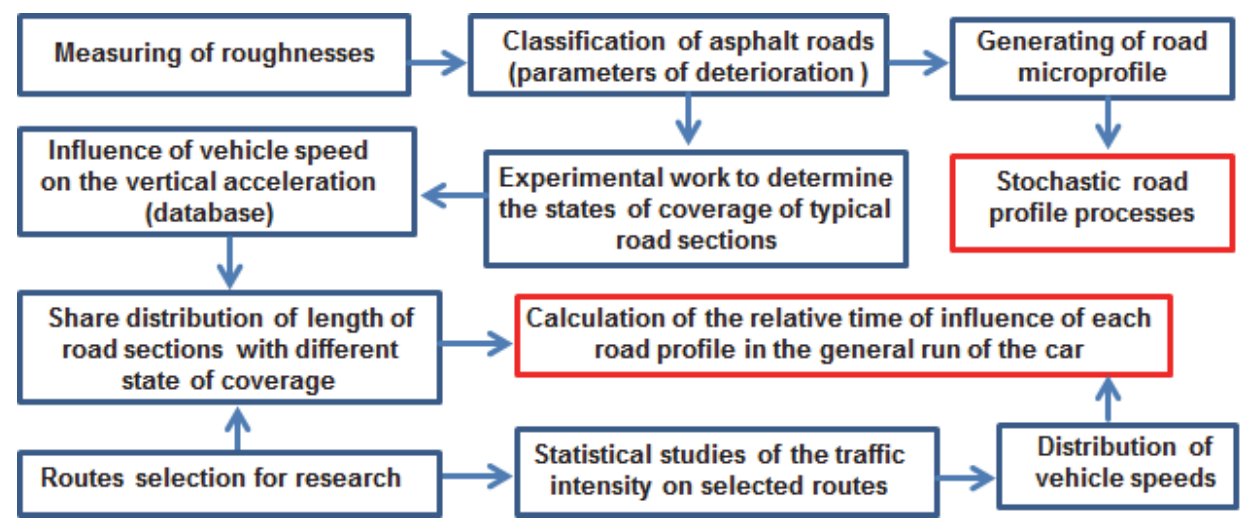

Figure 11. Methodology for preparing of random sampling of road impact

\section{Conclusion}

Methodology of construction of the generalized random sample of the road impacts in accordance with standard operating cycles of light commercial vehicles was received.

The methodology can be used to produce probabilistic models of the operating loading of elements of vehicles running on the roads of any region for life prediction of the parts of light commercial vehicles.

In this paper it is assumed that the vehicle tracks can pass through any part of the total length of roads in the region. In this case it is necessary to know the distribution of velocities of the vehicles on different types of roads.

The proposed approach in the paper provides fast simulation of disturbances (impacts) from the road to quantify the durability of automotive elements in conditions of limitation (or absence) of data about the distribution of vehicles run on different types of roads.

It is necessary to move to a model of spatial road impacts in further computer calculations of vehicle parts fatigue life. The transition should be carried out with the use of the approach described in [8]. To take into account the effect of the variable vehicle speed at stochastic stationary processes of road impacts the results of [9] should be used.

It is (still) in progress to find ways to further account of the basic elements of the road network (tram tracks, crossings, etc.) when generating the ordinates of a microprofile. The possibility of such add-ons due to the fact that the character of alternation of effects is unimportant for the fatigue calculation methods.

\section{Acknowledgement}

This research is performed with financial support of the Ministry of Education and Science of the Russian Federation within the framework of the project under contract № 
02.G25.31.0006 from 12.02.2013 (Resolution of the government of the Russian Federation on April 9, 2010 №218).

\section{References}

[1] Ogorodnov, S. M., Zezulin, D. V., Makarov, V. S., Tumasov, A. V.: Justification of methods of fatigue life estimation for the vehicle suspension's parts, Modern problems of science and education, No. 4, 2013

available at: www.science-education.ru/110-9695

[2] Andronik, A. V., Savkin, A. N., Gorobtsov, A. S.: Assessment of strength and fatigue life of structural elements of the car, Selected proceedings of the XXIII International innovation-oriented conference of young scientists and students. (in Russian) (MIKMUS-2011). Moscow, 2012

[3] Pavlenko, A. P., Galimyanov, I. D., Valeev, I. D.: An approach to the calculation of fatigue durability of structural trucks. Interuniversity collection of scientific works, "Design and analysis of technical systems".(in Russian) Naberezhnye Chelny, INEKA, pp. 67-73, 2007

[4] Pavlenko, P. D., Galimyanov, I. D.: Methods of forming of the model of road safety impact on supporting structures of the trucks for their calculation on the fatigue strength, Social and economic technical systems. Scientific technical journal on-line. (in Russian) Nab. Chelny: INEKA, no. 12, vol. 28., pp. 12-20, 2006

available at: http://kampi.bancorp.ru/scitech/base/nomer7

[5] Shleykher, A. A., Krylov, A. A.: Methods of forming of the model of road safety exposure, Dynamics of machines working processes, Collection of papers of allRussian scientific and technical conference (In Russian) Chelyabinsk, Publishing house YuUrGU, pp. 151-157, 2005

[6] Musarskiy, R. A.: Mathematical models of wheeled vehicles, Teaching medium (in Russia) - Publishing house of the Nizhny Novgorod State University named after N.I. Lobachevsky. Mathematical models of wheeled vehicles. Teaching medium. (in Russian) Publishing house of the Nizhny Novgorod State University. Named after N.I. Lobachevsky, p. 164., 2008

[7] Makarov, V. S., Zezyulin, D. V., Belyaev, A. V., Zubov, P. P., Vahidov, U. Sh., Redkozubov A. V., Belyakov V. V.: Mathematical model of the soil ground with plenty of typical discrete obstacles, Modern problems of science and education, no. 5, 2013 available at: www.science-education.ru/111-10472

[8] Dodds, C. J.: The laboratory simulation of vehicle service stress, Journal of Engineering for Industry, vol. 96, no. 2, pp. 391-398, 1974

[9] Peter, T., Bellay, A.: Integral transformation of road profile excitation spectra for variable vehicle speeds, Vehicle System Dynamics, p. 15., 1986 